\title{
Agente penitenciário elou pesquisador? Trabalho e pesquisa na prisão desde um lugar relacional
}

\author{
Penitentiary agent and / or researcher? Prison work and research from a \\ relational place
}

\author{
Francisco Elionardo de Melo Nascimento'
}

\section{Resumo}

Este artigo tem o objetivo de problematizar o trabalho e a pesquisa a partir de um lugar relacional para com as prisões cearenses. Narrado em primeira pessoa, o texto é um recorte de uma pesquisa etnográfica sobre o aprisionamento de travestis no Ceará. Trata-se de reflexões esboçadas desde o meu exercício profissional como agente penitenciário, ao trabalho etnográfico que fiz em três penitenciárias que aprisionam travestis. Aponto o lugar relacional como determinante para concessão da permissão para a entrada, permanência e interlocução com os sujeitos nas prisões que escolhi como campo de pesquisa, e implicou diretamente nas questões metodológicas e operacionais. Embasado nos dilemas metodológicos e operacionais da pesquisa etnográfica, me proponho a discutir o trabalho dos agentes penitenciários no cotidiano da prisão e os desafios enfrentados pelo pesquisador que estuda o campo em que atua profissionalmente. Destaco que, assumir papéis relacionais em um campo multissituado, implica em ser produzido no campo a partir de relações polissêmicas. 0 lugar relacional para com a prisão e a minha vinculação acadêmica, como acadêmico/pesquisador da sociologia, me permitiu pensar o rendimento das experiências entre presos, não-presos, Estado e travestis ocorridas no Ceará para os estudos sobre prisões, relações de gênero e sexualidade no Brasil.

Palavras-Chave: Prisão; Trabalho prisional; Pesquisa etnográfica; Lugar relacional.

\begin{abstract}
This article aims to problematize the work and research from a relational place to the prisons of Ceará. Narrated in the first person, the text is a clipping of an ethnographic research on the imprisonment of transvestites in Ceará. These are reflections sketched from my professional practice as a penitentiary agent, to the ethnographic work I have done in three penitentiaries that imprison transvestites. I point out the relational place as determinant for granting the permission to enter, stay and interlocate with the individuals in the prisons that I chose as research field, and directly involved in the methodological and operational issues. Based on the methodological and operational dilemmas of ethnographic research, I propose to discuss the work of penitentiary agents in prison daily life and the challenges faced by the researcher who studies the field in which he works professionally. I emphasize that assuming relational roles in a multisituated field implies being produced in the field from polysemic relations. The relational place for imprisonment and my academic connection as a sociology researcher allowed me to think about the income of experiences between prisoners, non-prisoners, state and transvestites in Ceará for studies on prisons, gender relations and sexuality in Brazil.
\end{abstract}

\footnotetext{
${ }_{1}^{1}$ Doutorando em Sociologia pelo Programa de Pós-Graduação em Sociologia da Universidade Estadual do Ceará (PPGS/UECE), Agente Penitenciário do Ceará (SEJUS/CE), Membro do Laboratório de Estudos Conflitualidades e Violência - COVIO. E-mail: elionardomelo@gmail.com. Cidade: Fortaleza.
} 
Keywords: Prison; Prison work, Ethnographic research; Relational place.

\section{Introdução}

A pesquisa e o trabalho na prisão já foram abordados, nas ciências sociais, de maneiras diversas. Os desafios de pesquisar a prisão e seus labirintos (SALLA, 2013) e/ou o trabalho fatigante dos profissionais da prisão (LOURENÇO, 2011; TAETS, 2012), impõem aos pesquisadores formas criativas e variadas de inserções diante das normas e regulamentos que afunilam o acesso ao interior dessas instituições e ao contato com a administração prisional, agentes penitenciários e presos. Deste modo, apresentar um olhar sobre as instituições carcerárias, é sempre lançar mão de uma visão singular, parcial e provisória que está sempre situada nas dinâmicas do cotidiano e limitada no tempo e aos espaços específicos. É importante destacar que, não se pode desenvolver uma análise sobre as dinâmicas prisionais sem considerar a fertilidade de mudanças e/ou reformas que, incessantemente, atravessam as prisões.

Ao longo de décadas, vem se constituindo um conhecimento sobre a temática da violência, criminalidade e do encarceramento, com destaque para estudos do direito, da psicologia, antropologia e sociologia. No âmbito dessas áreas temáticas, as prisões têm ganhado destaque com a crise na segurança pública, o encarceramento em massa e a atuação das facções criminosas dentro e fora dos estabelecimentos prisionais (FELTRAN, 2010; TELLES \& HIRATA, 2007; GODOI, 2011; CHIES, 2015; BARBOSA, 2006; SALLA, 2015).

No Brasil, o número de presos e presas tem crescido no decorrer dos anos com uma velocidade abrupta, desencadeando uma grave crise de superlotação que vem chamando a atenção de vários cientistas sociais (WACQUANT, 2001, 2007; SALLA, 2015; GODOI, 2015). Os dados produzidos pelo Departamento Penitenciário Nacional, referentes ao ano de 2016, mostram que a população prisional era de 726.712 pessoas para 368.049 vagas $^{2}$. Com um deficit de 358.663 vagas e com uma ocupação média de 197,4\%, o sistema prisional brasileiro, além de superlotado,

2 Dados do sistema prisional referentes a 30 de junho de 2016. 
mantém aprisionado um perfil de pessoas majoritariamente jovens, negros, com pouca escolaridade e de baixa renda (BRASIL, 2016) ${ }^{3}$.

O Brasil tem a terceira maior população prisional do mundo, ficando atrás apenas dos Estados Unidos e da China ${ }^{4}$. O contingente prisional brasileiro, segundo informações do referido órgão, cresceu $707 \%$ do ano de 1990 a 2016. Tal crescimento populacional de encarcerados é apontado como a consequência mais imediata do "endurecimento penal e das formas radicais de controle das pequenas ilegalidades" (SALLA; GAUTO; ALVAREZ, 2006, p. 330). Quando se trata da população prisional no âmbito dos estados federados, o Ceará ocupa a quinta posição no ranking dos estados com maior concentração de pessoas privadas de liberdade, totalizando 34.566 presos e presas. É importante destacar que o aumento vertiginoso da população carcerária e a atuação das facções criminosas, dentro e fora das prisões, têm provocado intensas mudanças no cotidiano das unidades prisionais.

O surgimento das facções criminosas no interior das unidades prisionais do Rio de Janeiro e São Paulo, nas décadas de 70 e 90, respectivamente, e seu espraiamento nas ruas, avenidas, "quebradas", bairros e em outros estados do Norte e Nordeste, têm evidenciado as prisões não mais como instituições desconectadas da sociedade, instituições totais (GOFFMAN, 1974), mas como instituições porosas (GODOI, 2015) com fronteiras cinzentas (BARBOSA, 2013) onde circulam pessoas, objetos e informações. Por isso, cada vez mais, têm-se discutido as conexões e relações estabelecidas entre as prisões e a sociedade (CUNHA, 2008). Tais questões se desenrolam em complexas relações institucionais e não institucionais que, desafiam os sistemas de justiça e penitenciário, mas

\footnotetext{
3 A respeito do aumento do encarceramento no Brasil nos governos de esquerda, ver Rodrigo Azevedo e Cláudia Cifali (2015).

4 De acordo com Wacquant $(2001,2012)$, o crescimento da população prisional brasileira e de outros países da América Latina e Europa está na esteira da política de "encarceramento em massa" dos Estados Unidos. O autor argumenta que os valores de justiça social e solidariedade, na perspectiva do "encarceramento em massa", foram substituídos pelo tratamento penal destinado à medicalização da pobreza e de seus correlatos como forma de higienização dos dejetos sociais nas cidades. Neste sentido, as mudanças do "Estado providência" para o "Estado penal" seguiram o remanejamento dos recursos da assistência social para o sistema carcerário e policial, tudo isso pautado na transfiguração da imagem daqueles que eram beneficiados pelas politicas sociais, sendo tratados como dependentes/ parasitas do Estado social.
} 
também os pesquisadores e pesquisadoras que se debruçam em analisar a temática.

No debate das prisões, o trabalho prisional pouco tem sido alçado como centralidade nas análises dos pesquisadores. Para Lourenço (2011), os agentes penitenciários, são os únicos profissionais que permanecem 24 horas por dia no interior das prisões. Lá, eles são responsáveis, pela dupla e contraditória, lida diária que consiste em promover, junto com outros profissionais, os meios possiveis de ressocialização e reintegração social dos apenados, e, ao mesmo tempo, manter e preservar a ordem e a disciplina, dispondo de precárias condições de trabalho. Estes profissionais compartilham, junto aos internos, mesmo que de forma distinta, do cotidiano de agruras das prisões que são evidenciadas pela superlotação, pelas precárias condições de habitação, dos serviços de saúde, de assessoria jurídica, social e educacional, dentre outros.

Taets (2012), ao pesquisar trajetórias de agentes penitenciárias em suas lidas diárias em presídios, argumenta que, mais do que trajetórias do cotidiano de trabalho nas prisões, os encontros dela com as interlocutoras possibilitaram a formulação de narrativas que extrapolaram o interior das prisões. De acordo com a autora, as histórias contadas por tais mulheres permitiram evidenciar as porosidades das fronteiras entre prisão e sociedade extramuros. A partir dos relatos, pôde perceber os fluxos de pessoas, materiais, ideias, sentimentos e convicções entre o interior do presídio e aquilo que se encontra por detrás dos muros, derrubando a ideia da rígida separação entre o dentro e fora do cárcere.

Ainda de acordo com a autora, as narrativas das suas interlocutoras são permeadas por diversas esferas da dor. Ou seja, trata-se das afetações de compartilhar o cotidiano de agruras da prisão e se sensibilizar com a experiência dolorosa das pessoas que estão reclusas. Essas afetações não ficam retidas nos espaços de trabalho ou mesmo são redimensionadas após os exaustivos plantões. Elas borram as fronteiras da prisão e acompanham os/as profissionais pelos bairros, ruas, em suas casas, tomam suas memórias e se revelam no próprio exercício narrativo. 
É pautando-me do exercício narrativo e experiência pessoal, como agente penitenciário e pesquisador, que me proponho a problematizar o trabalho e a pesquisa a partir de um lugar relacional para com as prisões cearenses. Descrevo e analiso o trabalho dos agentes penitenciários nos seus espaços de atuação profissional e minha experiência pessoal de pesquisa e produção do conhecimento a partir da vinculação acadêmica na sociologia. Nesta perspectiva, busco fomentar algumas reflexões sobre os desafios de realizar pesquisa etnográfica no campo de atuação profissional desde um lugar relacional para com as prisões.

Este artigo tem uma dupla finalidade. Além de fomentar uma discussão sobre o trabalho dos agentes penitenciários no cotidiano das prisões cearenses, evidencia os desafios de fazer pesquisa etnográfica no campo de atuação profissional. Para tanto, parto do lugar relacional que ocupo na prisão, para problematizar as questões que envolvem as restrições dos pesquisadores no acesso as prisões e, também, os desafios de trabalhar e pesquisar as e/ou nas prisões a partir do lugar que ocupo de agente penitenciário. Destaco que, as reflexões esboçadas neste texto, foram elaboradas na minha pesquisa de dissertação de mestrado (NASCIMENTO, 2018) que teve o objetivo de discutir o aprisionamento de travestis no Ceará a partir de uma etnografia multissituada (MARCUS, 1995) ${ }^{5}$. Portanto, as descrições e análises, aqui esboçadas, devem ser compreendidas, também, a partir do recorte e do campo de pesquisa multissituado do qual me propus etnografar.

O texto, narrado em primeira pessoa, tem o intuito de evidenciar uma experiência singular no cotidiano do trabalho e da pesquisa na prisão. Como disse Mallart (2014), a cadeia tem a capacidade de mudar a vida das pessoas. Entra na mente, nos sonhos e nos poros de quem trabalha, visita e de quem fica preso. Eu não tenho dúvidas de que a minha entrada e permanência na prisão me possibilitou novos caminhos como profissional, pesquisador e, acima de tudo, como ser humano que se afeta com sofrimento do outro.

\footnotetext{
5 A pesquisa contou com financiamento da Fundação Cearense de Apoio ao Desenvolvimento Científico e Tecnológico (FUNCAP). Agradeço a Natália Padovani pela sua primorosa leitura e compartilhamento de ideias que deram base a este texto.
} 


\section{O trabalhador prisional no cotidiano da prisão}

Foi em 2012 que tive meu primeiro contato com a prisão. Aquele espaço pareceu-me estranho, complexo e perigoso, mas de imediato tentei interiorizar que ali, na prisão, eu viveria uma experiência profissional singular, embora, naquele momento, meu sentimento em relação à profissão de agente penitenciário e sua atuação profissional no cotidiano prisional não me fascinavam na condição de sujeito. Era meu primeiro dia de estágio, e fui direcionado pela comissão organizadora do concurso de agente penitenciário de 2011 para o Instituto Penal Professor Olavo de Oliveira II (IPPO II) ${ }^{6}$. Era uma experiência nova e desafiadora, pois aquela seria a primeira das muitas visitas que faria às prisões cearenses.

Despir-se de todos os objetos não permitidos no interior da unidade prisional foi a primeira orientação que recebi na entrada da prisão. Em seguida, passei por dois "procedimentos"7 de "revista pessoal" - o primeiro foi executado com o auxílio de um detector de metais e o outro, pelas mãos do agente penitenciário plantonista, que tocou por cima da roupa os contornos do meu corpo. A revista tem o objetivo de impedir a entrada de "materiais ilícitos" no interior da unidade prisional, um "procedimento" de rotina que é repetido em cada pessoa que adentra a penitenciária. Após ser revistado, acompanhei um dos agentes penitenciários responsáveis pelo plantão para conhecer os espaços da unidade: setor administrativo, enfermaria, as oficinas de trabalho, os arredores, a cozinha e, também, as "vivências"8.

Abrir e fechar celas, fazer vigilância, vistoriar, revistar, escoltar, dar orientação, fazer o controle de entrada e saída de pessoas e objetos, mediar situações de conflito e conduzir presos para atendimentos, audiências, escola e oficinas são algumas das atividades internas e externas dos agentes

\footnotetext{
6 Presídio para presos julgados, transformado temporariamente em unidade para regime semiaberto, localizado no Complexo Penitenciário de Itaitinga I, município de Itaitinga. Foi inaugurado em 19 de setembro de 2002 .

7 Ao longo deste artigo os termos êmicos são identificados entre aspas, deixando claro que trabalho com duas fontes de interlocução, ora nossos interlocutores são as travestis com seus termos êmicos e o Estado com seus termos êmicos, sendo subjetivados por todos: agentes penitenciários, interno, internas, familiares e administração prisional.

8 "Vivência" é o mesmo que ala, "rua", pavilhão, porém com área para banho de sol, lazer e refeições.
} 
penitenciários no cotidiano da prisão9. Tais atribuições foram reafirmadas pelo profissional que supervisionava a mim e a outros sete estagiários que compunham o grupo.

Seguindo por um extenso corredor, observei assustado aquele amontoado de presos transitando tanto nas atividades da cozinha, da padaria e de outras oficinas de trabalho, como também assistindo aula ou aguardando atendimento dos técnicos (médico, enfermeiro, assistente social, psicólogo, odontólogo, entre outros). Cabisbaixos, os presos reviravam os olhos para o canto no intuito de observar quem eram aquelas pessoas. Os agentes plantonistas se sentiram incomodados com os olhares dos presos, e como de costume, ordenou-se aos presos a permanência da posição curvada dos ombros e cabeça.

Em pouco tempo de permanência naquele espaço, eu já percebia os olhares marcantes - um olhar cabisbaixo, tímido, atrevido que tudo quer ver e o outro olhar que monitora, limita, vigia e ordena. Cada movimento era atravessado por olhares, e todos ali procuravam tudo acompanhar e avaliar. Uma dupla vigilância sem lacunas. Eu observava tudo atentamente, mas também era observado e avaliado por cada ação direcionada, já que estava ali para executar as técnicas ensinadas nas aulas teóricas e práticas do curso de formação que duraram 40 dias.

O mau cheiro do IPPO II e de outras unidades prisionais que visitei posteriormente é uma das características marcantes das prisões no Ceará. No IPPO II, uma mistura de odores remetia a fezes e urina, além do lixo espalhado nos arredores da Unidade e a presença de ratos e gatos que conviviam harmonicamente por todo o espaço, reflexos da condição insalubre daquela prisão.

\footnotetext{
9 As atribuições do cargo de agente penitenciário foram definidas pela Lei $\mathrm{n}^{\circ} 14.582$, de 21 de dezembro de 2009, alterada pela Lei $\mathrm{n}^{\circ}$. 14.966 , de 13 de julho de 2011, que cria a carreira de Segurança Penitenciária e estabelece as atribuições de seus integrantes. Art. $1^{\circ}$ A carreira Guarda Penitenciária, integrante do Grupo Ocupacional Atividades de Apoio Administrativo e Operacional, prevista no item 2, do anexo I, da Lei $\mathrm{n}^{\circ} 12.386$, de 9 de dezembro de 1994, fica redenominada para carreira Segurança Penitenciária e estruturada na forma do anexo I desta Lei, passando os Agentes Penitenciários a ter as seguintes atribuições: atendimento, vigilância, custódia, guarda, escolta, assistência e orientação de pessoas recolhidas aos estabelecimentos penais estaduais. O conteúdo da lei na întegra está disponível em: < http://sindaspce.org.br/downloads/lei-14966.pdf>. Acesso em 19$10-2017$.
} 
Com a finalização das etapas do concurso, fui nomeado e lotado para exercer minhas atribuições profissionais na Penitenciária Industrial Regional de Sobral (PIRS) ${ }^{10}$. Era 25 de março 2013, uma manhã de segunda-feira, quando cheguei à PIRS. Uma confusão de sentimentos e sensações me tomou naquele instante, uma vez que não sabia como me comportar naquele espaço que tão logo seria meu cenário profissional na função de agente penitenciário.

A inexperiência em relação aos trâmites de trabalho me imputava um estranhamento avassalador, talvez em decorrência das inúmeras histórias de violência ocorridas no interior das prisões ou em função das características daquele espaço que tinha muralhas altas, chão e paredes úmidas - resultado de infiltrações -, pouca iluminação, cheiro forte de dejetos humanos e de gatos, lixo e fumaça de cigarro, espalhados por todo o seu interior. Tais características misturavam-se ao fluxo intenso de presos e profissionais que transitavam freneticamente pelo corredor central, em idas e vindas ao longo de todo o espaço. Eu me sentia um alienígena usando aquela vestimenta de cor preta, composta por calça tática, coturno e camisa com o brasão da profissão bordado no lado esquerdo do peito.

Naquele momento, eu iniciava minha trajetória como profissional e, um pouco mais tarde, como pesquisador. Um lugar relacional para com a prisão que me imputa aproximações, repulsas, confiança, desconfiança, estranhamento e familiaridades, mas acima de tudo, me possibilitou uma rede de afetos que foram determinantes na minha trajetória no cárcere. Esse lugar relacional que ocupo me permitiu formular um olhar a respeito das instituições com as quais mantive contato, fundamentado nas interlocuções e nuances, ora relembradas, ora vivenciadas em meio aos profissionais, visitantes, internos e internas que envolve transversalmente assuntos que vão além dos muros e entorno das prisões.

Ali, na prisão, meu corpo e minhas emoções foram atravessados pelas dinâmicas presentes nas instituições com as quais mantive vínculo.

\footnotetext{
10 A PIRS é uma penitenciária masculina para presos em cumprimento de pena privativa de liberdade em regime fechado, única da região norte e noroeste do estado do Ceará. Foi inaugurada em 22 de março de 2002 e tem capacidade total para 492 internos, embora, no decorrer desta pesquisa, a Unidade abrigava um contingente prisional que variava entre 650 e 700 presos.
} 
Como profissional iniciante, vários questionamentos surgiram a respeito da minha atuação: como me comportar diante de um espaço hierárquico, autoritário, perigoso e insalubre? Quais os limites da minha aproximação com os internos? Como conviver com a intensidade dos plantões, que têm duração de 72 horas ininterruptas? ${ }^{11}$ Essas e outras questões me acompanharam por dias e, aos poucos, fui me adaptando à intensa rotina da prisão. Passei a lidar melhor com as atribuições contraditórias da profissão, valendo-me do diálogo para a resolução dos conflitos.

\section{O encontro do agente penitenciário com a pesquisa desde um lugar relacional}

No cotidiano da PIRS, o contato com os internos é constante, principalmente com aqueles que desenvolvem algumas atividades de trabalho no interior da unidade prisional. Eles convivem o dia inteiro no mesmo espaço dos profissionais da segurança prisional - nos corredores, na cozinha, no refeitório e na padaria. A todo instante, os presos transitam no interior da Unidade, mas sempre pedindo autorização dos agentes penitenciários, que se dividem em postos estratégicos de vigilância e de controle das pessoas e dos objetos que transitam naquele espaço ${ }^{12}$. Além do viés hierárquico, notoriamente identificado, entre presos trabalhadores e agentes penitenciários, há também um grau de estima e confiança. Foi a partir dessa aproximação entre internos trabalhadores e profissionais da

\footnotetext{
11 A lei $n^{\circ} 14.582$ de 21 de dezembro de 2009 elencou em seu artigo $4^{\circ}$ o regime de trabalho dos agentes penitenciários - "os agentes penitenciários estão submetidos ao regime de plantão de 12 x 36 horas (12 horas de trabalho seguidas de 36 horas de descanso), podendo haver revezamento no período diurno e noturno" (grifos meus entre parênteses). Porém, essa escala de plantões não é seguida em nenhuma unidade prisional do estado do Ceará. Os agentes penitenciários seguem dois distintos regimes de plantões que giram em torno da localização do estabelecimento prisional a que estão vinculados. Os profissionais lotados na Região Metropolitana de Fortaleza trabalham 24x72 (24 horas de trabalho seguidas de 72 horas de descanso), já os demais com exercício funcional nas outras cidades cearense seguem o regime de $72 \times 216$ (72 horas de trabalho seguidas de 216 horas de descanso) que corresponde a três dias trabalhados seguidos de nove dias de descanso. O conteúdo completo da lei está disponivel em: < http://sindaspce.org.br/downloads/lei-14582.pdf>. Acesso em: 04-10-2017.

12 Espaços como a recepção e o quadrante 1 são ocupados 24 horas por dia por um(a) agente penitenciário plantonista. As guaritas da muralha também são ocupadas intermitentemente por policiais militares. A presença dos policiais militares nas muralhas é justificada pelo quantitativo insuficiente de agentes penitenciários, uma vez que o Regimento Geral dos Estabelecimentos Prisionais do Ceará prevê os agentes penitenciários como responsáveis por todas as atividades de segurança no âmbito do sistema penitenciário do estado. O documento está disponivel em: <http:/ /www.sejus.ce.gov.br/index.php/leia-mais/ 14-lista-de-noticias / 1832--publicado-novoregulamento-do-sistema-penitenciario-do-ceara>. Acesso em 17-10-2017.
} 
segurança que tive o primeiro contato com Renata ${ }^{13}$, travesti interna na PIRS.

Ela era a responsável pela limpeza. Habilidosa, cativava os agentes penitenciários com seu jeito solícito. Renata, quando no exercício de suas atividades de trabalho, estava totalmente despida dos aspectos femininos performatizados (BUTLER, 2012) em seu corpo, vestia o uniforme padrão fornecido pela Unidade - um short de cor laranja e uma blusa branca estampada com o nome "Sistema Penitenciário Cearense". Não era novidade para mim que a travesti estivesse visualmente desprovida dos elementos que ela considerava componentes da sua identidade de gênero - cabelos longos, seios hormonizados e roupas femininas, entre outros -, uma vez que já conhecia o regimento interno da unidade penitenciária que é destinada a homens. De qualquer forma, inquietavam-me as invasivas intervenções impetradas contra os aspectos identitários performatizados por Renata.

Sara Salih (2013, p. 21), ao interpretar o pensamento de Butler no tocante à performatividade de gênero, disserta que o trabalho da autora defende que as identidades não podem ser consideradas fixas e autoevidentes, mas inseridas em processos pelos quais a identidade é construída no interior da linguagem e do discurso. Butler está menos preocupada com o caráter de formação do sujeito como indivíduo e na experiência individual do que em analisar o processo genealógico pelo qual o indivíduo vem a assumir sua posição como sujeito.

\begin{abstract}
Uma investigação genealógica da constituição do sujeito supõe que sexo e gênero são efeitos - e não causas - de instituições, discursos e práticas; em outras palavras, nós, como sujeitos, não criamos ou causamos as instituições, os discursos e as práticas, mas eles nos criam ou causam, ao determinar nosso sexo, nossa sexualidade, nosso gênero. As análises genealógicas de Butler vão se concentrar no modo como o efeito-sujeito, como ela chama, se dá, e ela sugere, além disso, que há outros modos pelos quais o sujeito poderia se "efetuar". Se o sujeito não está exatamente "lá" desde o começo (isto é, desde o momento que nasce), mas é instituído em contextos específicos e em momento específicos (de tal modo que o nascimento em si se constitui numa cena de subjetivação), então o sujeito pode ser instituído diferentemente, sob formas que não se limitem a reforçar as estruturas de poder existentes (SALIH, 2013, p. 21-22).
\end{abstract}

13 A interlocutora é identificada por nome fictício com a finalidade de preservar sua identidade. 
As performatividades de gênero dispostas no discurso de Renata a partir dos atributos considerados por ela como femininos, e materializados em seu corpo, fazem parte de uma teia de discursos subjetivados ao longo de sua formação como sujeito e que são associados à feminilidade das travestis. A discussão de Butler, sobre performatividade de gênero, nos permite pensar a respeito dos aspectos masculinos e femininos performatizados por todos na prisão, seja os agentes prisionais, os internos e as travestis. Toda produção corporal é performance de gênero. Assim, tanto o uniforme da prisão, o fardamento dos agentes quanto os objetos utilizados pelas travestis são performances de gênero.

Certa vez, fui acompanhar Renata na faxina do alojamento dos agentes penitenciários e, enquanto vigiava a execução do seu trabalho e a ajudava afastando os móveis, ela me contou um pouco de sua vida - do período das transformações ${ }^{14}$ corporais engendradas pela travestilidade ${ }^{15}$, do envolvimento com a "criminalidade" e também do ingresso e do cotidiano na prisão. Com lágrimas nos olhos, a travesti relatou o período da sua entrada na PIRS:

Eu já sofri muito aqui. Quando eu entrei aqui, eu era bonita! Eu tinha os cabelos grandes e os peitões hormonizados. Ninguém dizia que eu não era uma mulher, até os agentes disseram que eu não podia ficar aqui porque aqui é uma unidade masculina, mas o policial que me trouxe disse que eu era uma travesti. Logo que cheguei, rasparam meus cabelos e me disseram que não eram permitidas roupas de mulher na penitenciária. Eu fiquei arrasada! Eu chorava todo tempo durante umas duas semanas. Foi então que a antiga diretora me deu a oportunidade de trabalhar aqui, na limpeza.

Ao ingressar na PIRS, Renata teve suas singularidades desrespeitadas, profanadas, como definiu Goffman (1974, p. 24) ao chamar de profanação do eu as invasivas modificações incutidas nos indivíduos encarcerados. Tratase das mudanças na carreira moral, agindo nas crenças, nos preceitos e na

\footnotetext{
14 Uso o termo "transformação", aqui, com o mesmo significado que lhe atribuiu Larissa Pelúcio (2005, p. 225, grifos meu entre colchetes) para demarcar o "processo de feminilização [dos meninos em travestis] que se inicia com a extração dos pelos da barba, pernas e braços, afina as sobrancelhas, deixa o cabelo crescer e passa a usar maquiagem, [fazer uso de hormônios] e roupas consideradas femininas nas atividades fora do mundo da casa".

15 O termo "travestilidade" foi proposto por Pelúcio (2009) com a finalidade de caracterizar a multiplicidade das vivências implicadas na construção e desconstrução do corpo travesti. As etnografias de Hélio Silva (2007), Marcos Benedetti (2005), Don Kulick (2008), Alexandre Vale (2005) e Larissa Pelúcio (2009) abordam a construção e reconstrução dos corpos das travestis nos espaços de prostituição.
} 
identidade pessoal com o intuito de adequar os presos aos parâmetros institucionais. Nesse sentido, ao suprimir os aspectos identitários performados pelas travestis, as instituições prisionais reafirmam um padrão binário de identidade de gênero de tal forma que as pessoas que não expressam características definidas para homem e mulher - masculino e feminino, respectivamente -, são suprimidas de seguir vivenciando suas

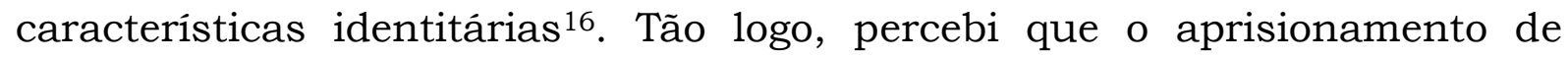
corpos na prisão é também o sufocamento de identidades de pessoas que não se enquadram nos gêneros inteligiveis (BUTLER, 2002), ou seja, aquelas pessoas que, em certo sentido, não instituem e nem mantêm relações de coerência entre sexo, gênero, prática sexual e desejo ${ }^{17}$. Essa inteligibilidade disposta pela norma heterossexual, de acordo com Butler, é a mesma que as torna abjetas. Dessa forma, ao desenvolverem suas interações com o mundo a partir do trânsito entre o feminino e o masculino, as travestis não são apropriadamente generificadas, representando os corpos que servem para balizar as fronteiras da normalidade como fruto do discurso hegemônico que circunscreve os corpos que não importam.

Com o intuito de adequar os internos aos parâmetros institucionais são realizadas as vistorias nas celas que tem como objetivo a apreensão de "materiais ilícitos" e "não permitidos" (chips, celulares, drogas, bebidas alcoólicas, brincos, pulseiras, entre outros) ${ }^{18}$. Dentre tais materiais apreendidos estão as roupas e outros adereços femininos negociados pelas travestis com as visitantes, tendo em vista a negativa da unidade prisional em permitir acesso a eles por via institucional. Tal estratégia é uma das formas mais comuns de aquisição dos itens. Após a vistoria nas celas, cada interno é revistado perante os demais presos e dos profissionais. Despidos e

\footnotetext{
16 Isso ocorre, também, em outras instituições públicas e políticas de governo, tais como: Delegacias da Mulher; Equipe de Saúde da Família, políticas de empréstimo para construção da casa própria pela Caixa Econômica Federal, situações de internamento de doentes em hospitais públicos, enfim, uma rede de funcionamento que cria regras e legitima sujeitos a partir do binarismo e apagamento de sujeitos da diferença.

17 Para uma discussão aprofundada sobre o aprisionamento de travestis no Ceará, ver minha dissertação de mestrado (NASCIMENTO, 2018). Sobre o aprisionamento de travestis no eixo SulSudeste, ver Passos (2014), Ferreira (2014) e Zamboni (2017).

18 As formas de inserção de "materiais ilícitos" e "não permitidos", nas unidades prisionais, são diversas. Dentre as mais comuns estão os "rebolos" (pacotes envoltos por esponjas contendo materiais ou substâncias que são arremessados por cima da muralha para o interior das prisões), os levados junto às visitantes e por meio da corrupção de servidores públicos terceirizados e efetivos.
} 
enfileirados um ao lado dos outros, os presos são chamados um a um para o "procedimento" de "revista pessoal" executado pelos agentes penitenciários com o intuito de encontrar "materiais ilícitos" ou "proibidos" abstrusos em seus corpos: "levante os braços, espalme as mãos, abra a boca e levante a língua, mexa os cabelos e agache três vezes de frente de costas para mim”, dizia um agente penitenciário. O mesmo ritual é protagonizado pelas travestis e acompanhado por chacotas, ridicularizações, risos e zombarias. Não demorei a perceber que, no espaço prisional, pode existir uma marginalização excessiva a um determinado grupo já segregado com o aprisionamento.

Foi a partir das observações, dos diálogos e das vivências como agente penitenciário na PIRS que surgiu a intenção de pesquisar travestis em situação de privação de liberdade no Ceará. Já na minha pesquisa de graduação em Serviço Social, tomei a prisão como foco (NASCIMENTO, 2015) ${ }^{19}$ e, a partir de então, pude perceber que pesquisar prisão ou na prisão requer, também, uma discussão do lugar social que ocupo na instituição e/ou como sujeito com formação acadêmica nas Ciências Humanas. Minhas intenções como pesquisador foram formuladas a partir da minha vivência como profissional, tendo se materializado, de fato, a partir do ingresso como pesquisador em campo. Parto, assim, de um lugar relacional para com a prisão que é o de agente penitenciário. Este lugar relacional foi determinante para concessão da permissão para a entrada, permanência e interlocução com os sujeitos nos locais que escolhi como campo, e implica diretamente nas questões metodológicas e operacionais da pesquisa. Portanto, esta é uma etnografia afetada (AGUIÃO, 2014) desde o princípio da inserção como pesquisador no campo e por minhas relações pessoais e profissionais com os múltiplos atores do espaço prisional que, obviamente, "dizem sobre aquilo que pode ser visto e compreendido desde um lugar bastante específico e logicamente traz também a marca de todos os não-

\footnotetext{
19 A pesquisa denominada "Entre grades, muralha e vivência: uma etnografia da ressocialização na Penitenciária Industrial Regional de Sobral” teve o objetivo central de analisar a execução das técnicas e estratégias para ressocialização dos internos na PIRS a partir da percepção dos agentes penitenciários.
} 
vistos, não-ditos e inobserváveis deste mesmo posicionamento" (AGUIÃO, 2014, p. 20).

Seguido o percurso do lugar relacional que ocupo no campo de pesquisa, tento, aqui, problematizar e discutir uma das esquivações usuais na maioria dos trabalhos que se debruçam sobre as prisões. Refiro-me às formas chapadas por meio das quais, insistentemente, os agentes penitenciários são descritos e reiteradamente colocados na posição figurativa daqueles que abrem e fecham portões, pedem documentos, fazem vistorias e revistas vexatórias, mas que muitas vezes não são nomeados ou pessoalizados nas relações tecidas pelos pesquisadores/voluntários/visitantes das prisões. Os agentes penitenciários partilham as agruras da prisão. Eles convivem e dividem os mesmos espaços esquadrinhados por normas e regras, se afetam e são afetados por toda a estrutura e dinâmicas que permeia as instituições prisionais, além de vivenciarem algumas relações que extrapolam os muros e tomam a cidade, os bairros, ruas, suas casas, suas vidas. Não afirmo que exista uma relação de igualdade entre os que custodiam e os que são custodiados, tão pouco que se assemelham os papéis sociais representados por cada um, mas destaco o intercruzamento das situações e compartilhamentos a partir da experiência carcerária. Além da não pessoalização, a escassez de pesquisas com enfoque na sociabilidade desses profissionais incorre em ausências mais constantes de parte das produções bibliográficas sobre prisões no Brasil.

A prisão como campo de pesquisa tem lançado debates que colocam em foco esse dispositivo de maneiras diversas e em posições estratégicas variadas (GODOI; MALLART, 2017)20. Contudo, as dificuldades de acesso e permanência nas unidades prisionais assentam os pesquisadores sob as contingências do espaço institucional impressas nas dificuldades de "conseguir permissão para estudar aquilo que se quer estudar, ter acesso às pessoas que se quer observar, entrevistar ou entregar questionários" (BECKER, 1999, p. 34).

20 A respeito da variedade de pesquisas na prisão e em seu entorno, ver a apresentação de Rafael Godoi e Fábio Mallart no dossiê "Dados e Atualidades da Pesquisa em Prisão no Brasil" publicado pela Aracê - Direitos Humanos em Revista (GODOI; MALLART, 2017). 
Pesquisadores e pesquisadoras utilizam-se de formas variadas para ter sua entrada permitida na prisão. A inserção nos espaços prisionais pode ser concedida a partir de uma negociação com a administração penitenciária (DIAS, 2011; PADOVANI, 2015), que, normalmente, exige um parecer do Comitê de Ética em Pesquisas, órgão que regula as pesquisas envolvendo seres humanos a partir de normativa especifica ${ }^{21}$; ou a partir de outras possibilidades de ingresso, concedidas para visitantes - o pesquisador pode visitar a prisão na condição de parente do interno (BIONDI, 2010) ou como voluntário de uma instituição religiosa, a exemplo da Pastoral Carcerária (GODOI, 2015). Essas formas de inserção do pesquisador/visitante 22 e a liberação formal guiam os pesquisadores a um público direcionado.

O lugar relacional que ocupo na prisão me possibilitou uma visão particular do contexto prisional, além de possibilitar meu acesso às instituições que escolhi como campo de pesquisa, às pessoas com quem mantive interlocução e a outras informações limitadas pelo controle da administração penitenciária ${ }^{23}$.

Inicialmente, elegi a PIRS como campo de pesquisa, porém, com as mudanças ocorridas no sistema penitenciário cearense a partir das rebeliões de maio de 2016 e com a visibilidade dos grupos criminais no cotidiano das prisões (NASCIMENTO, 2017), julguei necessário expandir a pesquisa para outras duas unidades prisionais recém-inauguradas e que abrigam travestis em cumprimento de pena privativa de liberdade no Ceará. Portanto, a pesquisa teve três instituições como lócus: a Penitenciária Industrial Regional de Sobral (PIRS), o Centro de Execução Penal e Integração Social Vasco Damasceno Weyne (CPIS) ${ }^{24}$ e a Unidade Prisional Irmã Imelda Lima

\footnotetext{
$21 \mathrm{O}$ debate das questões éticas nas pesquisas das ciências sociais trouxe inúmeras divergências ao modelo ético estabelecido nas pesquisas pelas ciências da saúde. Somente em abril de 2016 foi lançada a resolução de $n^{\circ} 510$ pelo Conselho Nacional de Saúde, que estabelece regras específicas para as pesquisas nas Ciências Sociais e Humanas. Neste periodo, a minha pesquisa já estava em curso, portanto, ela não foi submetida à aprovação do Comitê de Ética. Pelúcio (2009) e Ferreira (2014) fazem em suas pesquisas uma abordagem a respeito dessa discussão.

${ }^{22} \mathrm{~A}$ respeito da discussão da dupla inserção no dispositivo e das dificuldades em ter acesso a determinados assuntos, pessoas e espaços de acordo com a entrada na prisão para realizar pesquisa, ver Biondi (2010) e Godoi (2015).

23 O ingresso no PPGS/UECE fundamentou o afastamento das minhas atribuições profissionais junto à Secretaria de Justiça e Cidadania do Ceará por um periodo de dois anos.

24 A CPIS foi inaugurada em novembro de 2016. É a maior penitenciária do Ceará com capacidade total para 1.016 internos, está localizada na Região Metropolitana de Fortaleza, município de Itaitinga,
} 
Pontes $^{25}$. É indispensável pontuar que não me propus a fazer uma etnografia das instituições, uma vez que a minha intenção foi discutir o aprisionamento das travestis a partir das questões contextuais que envolviam tanto as diretrizes institucionais como as relações pautadas entre os múltiplos atores nas prisões: internos, profissionais e visitantes.

Em todas as unidades, ao se referirem a mim, os diretores e agentes penitenciários diziam algo como: "Esse é um colega nosso, agente penitenciário que está desenvolvendo sua pesquisa de mestrado aqui”. Tal apresentação era agenciada pelo lugar relacional que ocupo na prisão e me atribuía status de pessoa "insuspeita”, ou seja, alguém autorizado a observar o cotidiano das três penitenciárias durante as incursões etnográficas, além de me possibilitar o contato privilegiado com minhas interlocutoras travestis em reclusão.

Embora a minha condição de agente penitenciário tenha me proporcionado privilégios de acessos na prisão, as minhas intenções politicas em pesquisar gênero e sexualidade a partir do aprisionamento de travestis foram questionadas e consideradas suspeitas por alguns profissionais. Não é menos importante destacar aqui que meu corpo e minha sexualidade foram objetos de suspeição e análise. Tornaram-se frequentes as insinuações a respeito da minha orientação sexual. Ora, com qual finalidade um profissional da segurança penitenciária tem interesse de pesquisar travestis senão por similitude? Não seria mais coerente que pesquisasse questões no âmbito das atribuições ou sociabilidade dos agentes na prisão ou situações semelhantes? A resposta para estes e outros questionamentos já estava formulada. Por repetidas vezes ouvi algo do tipo: "Ele está pesquisando isso porque quer defender a irmandade”. A resposta era clara! Alguns já não se furtavam em insinuar, direto ou indiretamente, que eu era "baitola"26

\footnotetext{
e é uma unidade prisional integrante do Complexo Penitenciário Estadual de Itaitinga II. No período de minha imersão em campo, a Unidade abrigava 1.937 pessoas em cumprimento de pena.

25 A Unidade Prisional Irmã Imelda Lima Pontes, inaugurada em julho de 2016, é uma penitenciária com capacidade para 200 internos e internas. Destinada a presos com características consideradas singulares nas prisões da Região Metropolitana de Fortaleza, o presídio abriga presos deficientes, idosos, gays, bissexuais, travestis, transexuais e primários de crimes prescritos na Lei Maria da Penha.

26 "Baitola" é um termo cearense que significa "viado". Os dicionários de português grafam veado, mas, em sotaque cearense acentua-se o "i" , de viado. Ou seja, refere-se a alguém que desenvolve relações sexuais e afetivas com pessoas do mesmo sexo.
} 
também. Tais reações partem de uma suposta incompatibilidade em exercer a função de agente penitenciário e pesquisar gênero e sexualidade a partir de travestis na prisão, ou melhor, dizendo, pertencer à segurança penitenciária e ter orientação sexual não heterossexual. Diz também respeito à inutilidade de pensar a partir do gênero. Pensar o Estado é pensar uma narrativa totalizante, masculina e nunca um ponto de vista possivel.

Com as travestis, a pressuposição da minha orientação não heterossexual, certamente, foi importante para um contato mais estreito no âmbito das interlocuções. De fato, as travestis também compartilhavam a suspeição dos agentes penitenciários pelo meu interesse em pesquisar a temática. Embora nenhuma delas tenha perguntado se eu era ou não homossexual, nos momentos que expunham prazeres pela prática do intercurso sexual colocavam frases do tipo - "você sabe como é, né!". As frases inferiam formas de diálogo com alguém que era do meio, um "entendido": alguém que potencialmente as tomem como parceiras sexuais.

Mas, se por um lado o meu vínculo profissional me possibilitou a aproximação com as travestis mantidas na prisão, por outro, limitou seus discursos, principalmente, no que diz respeito às "atividades ilícitas" ou à posse de objetos "não permitidos" no interior das penitenciárias. Isso é compreensivo, tendo em vista que ao exercer a função de agente penitenciário eu estava encarnado pelo Estado policial (AGUIÃO, 2014)27. Ora, o Estado é feito pelo cotidiano dos agentes penitenciários, das assistentes sociais, dos pesquisadores das universidades, mas também dos religiosos que visitam as unidades prisionais. O Estado somos todos nós. Porém em algumas relações, alguns são mais "Estado" do que outros. No caso das relações para com as pessoas em cumprimento de pena, por exemplo, agentes de segurança são a corporificação do Estado, mais do isso, são a corporificação do Estado Policial.

Nas duas penitenciárias da Região Metropolitana de Fortaleza, CPIS e Irmã Imelda Lima Pontes, as travestis pareciam não hesitar em relatar algumas "atividades ilícitas" no interior da prisão, seja em relação ao uso de

\footnotetext{
27 Para Silvia Aguião, o "Estado encarnado" tem seu sentido imiscuído em práticas e enunciados que podem "significar ou estar significado em múltiplos lugares, objetos e/ou pessoas" (2014, p. 13).
} 
substâncias ou ao trânsito de "materiais ilícitos". Em uma das rodas de conversa que fiz com as travestis, o meu entrosamento com as interlocutoras foi tão fluente que uma delas me pediu um contato telefônico para continuarmos a conversa à distância. A situação tornou-se embaraçosa, já que o uso de celulares no interior das unidades prisionais é proibido. Trocar número de telefones seria naturalizar um hábito de contravenção por parte da minha colaboradora. Eu logo tratei de me sair da situação embaraçosa, dizendo que eu não utilizava este meio de comunicação ${ }^{28}$. Em outro momento, enquanto aguardávamos a vinda dos agentes penitenciários da Unidade para abrir o cadeado da sala onde eu e as minhas interlocutoras estávamos trancados realizando uma roda de conversa, três das travestis se aproximaram e elogiaram a minha aparência física. Uma delas disse: “Meninas, vamos 'fazer um duzentos' nele?". A frase foi seguida de muitos risos. Confesso que fiquei um pouco desconcertado, pois eu já sabia que "fazer um duzentos" seria explorar uma relação sexual não consentida, um estupro. A palavra "duzentos" refere-se ao artigo do crime prescrito no Código Penal Brasileiro29. Embora surpreso e tímido, tratei de continuar interagindo sem demonstrar meu espanto pela situação que julguei naquele momento, inusitada e constrangedora.

Na PIRS, unidade prisional com a qual mantenho vínculo profissional, o contato com as interlocutoras teve um formato mais formal. Nas entrevistas, as travestis se negaram a compartilhar experiências na prisão que envolvessem "atividades ilícitas”. Ora, não é difícil entender as negativas das informações. Embora eu tenha explicado os procedimentos éticos da pesquisa e que o uso dos relatos seria restrito à pesquisa, a representação que me imputavam durante as conversas não era apenas a de pesquisador, mas também a do agente penitenciário (a pessoalidade do Estado repressor), que estabelece com elas, no cotidiano de trabalho, relações desiguais e

$28 \mathrm{O}$ uso de aparelhos celulares no interior das unidades prisionais é proibido. O Código Penal Brasileiro define em seu Art. 349-A: "Ingressar, promover, intermediar, auxiliar ou facilitar a entrada de aparelho telefônico de comunicação móvel, de rádio ou similar, sem autorização legal, em estabelecimento prisional. Pena: detenção, de 3 (três) meses a 1 (um) ano". A Lei de Execução Penal prevê falta grave para os presos que forem flagrados com celulares no interior das unidades prisionais. Sobre o uso de tecnologias na prisão ver Bruna Bumachar (2012).

29 "Duzentos" faz referência aos presos que cometeram crimes sexuais prescritos no artigo 213 do Código Penal Brasileiro - "Constranger alguém, mediante violência ou grave ameaça, a ter conjunção carnal ou a praticar ou permitir que com ele se pratique outro ato libidinoso". 
hierárquicas, fazendo o uso progressivo da força em função do disciplinamento institucional.

Para as travestis da PIRS, algumas informações poderiam trazer riscos à segurança delas dentro e/ou fora da unidade prisional. A alcunha de "cabueta"30, além de comprometer a convivência delas junto aos demais internos, as deixariam passiveis a severas punições. O grau de intimidade com as interlocutoras rompeu outros parâmetros do contato entre pesquisador e pesquisadas ou de agente penitenciário e detentas. Por vezes me emocionei com o contexto de sofrimento explorado nos relatos, outras me surpreendi com o grau de intimidade adquirida no decorrer das interações em campo ${ }^{31}$. As fronteiras entre eu e minhas interlocutoras, avezadas pelo lugar relacional que ocupo na prisão, mostravam-se, às vezes, rígidas e outras bastante permeáveis.

\section{Considerações finais}

Trabalhar e pesquisar as e nas prisões a partir de um lugar relacional implica em algumas questões/situações específicas, e outras colocadas a qualquer pessoa que se aventure realizar pesquisa de campo no universo carcerário. O campo prisional é atravessado por múltiplos discursos que originam incessantes mudanças, percebidas em seu cotidiano e intensificadas pelo número cada vez maior de pessoas privadas de liberdade nestes estabelecimentos.

Superlotação, condições insuficientes de subsistência, laborais e educacionais, e o fluxo intenso de pessoas, objetos, informações e ideais são características das prisões comumente apontadas por pesquisadores. Tais características lançam novas problemáticas de pesquisa, desde que os muros e a presença de profissionais da segurança - fortemente armado exercendo vigilância, disciplina e o controle de entrada e saída, já não impedem as múltiplas conexões entre o prisional e o urbano e a atuação de grupos criminais no fora/dentro das prisões.

\footnotetext{
30 "Cabueta" é uma derivação de alcaguete, cagueta e sinônimo de dedo-duro. Sobre os/as caguetas em penitenciárias paulistas ver Padovani (2015, p. 48-49).

${ }^{31} \mathrm{Em}$ duas entrevistas, uma realizada na PIRS e outra na casa de uma interlocutora, as travestis, ao relatarem suas experiências com os usos dos hormônios femininos, expuseram seus seios volumosos para que eu me certificasse da eficácia do uso prolongado da medicação.
} 
Agentes penitenciários são personagens próprios das prisões desde a origem das mesmas. Eles são responsáveis por toda a rotina de trabalho (disciplina, escolta, assistência segurança, controle) desses espaços, convivem e se afetam com o cotidiano de escassez e agruras, mas, dificilmente, são cotados como centrais nas análises das pesquisas sobre prisões no Brasil. Um dos objetivos deste texto é discutir o cotidiano de trabalho desses profissionais e, desta forma, problematizar as formas chapadas por meio das quais, insistentemente, os agentes penitenciários são descritos e reiteradamente colocados na posição figurativa daqueles que abrem e fecham portões, pedem documentos, fazem vistorias e revistas vexatórias, mas que muitas vezes sequer são nomeados ou pessoalizados nas relações tecidas pelos pesquisadores das prisões.

Agentes penitenciários são protagonistas da intensa e desgastante rotina de trabalho em meio às agruras e insuficiências da prisão. Resistem, se afetam e são afetados por múltiplas condições de vida e situações cotidianas, como tentei mostrar, ao longo deste texto, pautando-me do exercício narrativo desde o lugar relacional que ocupo, como pesquisador e trabalhador do universo prisional.

Diante de todas as descrições e reflexões apresentadas ao longo deste artigo, afirmo que assumir papéis relacionais em um campo multissituado implica em ser produzido no campo a partir de relações polissêmicas (PADOVANI, 2015). E, por mais que possa ser contraditório, exercer o papel de agente penitenciário não me exclui de manter relações e interlocuções com pessoas em privação de liberdade, cuja finalidade é discutir as múltiplas tensões e narrativas que envolvem o aprisionamento de travestis. Embora, em algumas ocasiões, as tramas apareçam visiveis e outras eclipsadas. Pelo contrário, meu lugar relacional para com a prisão e a minha vinculação acadêmica me permite pensar o rendimento das experiências entre presos, não-presos, Estado e travestis ocorridas no Ceará para os estudos sobre prisões, relações de gênero e sexualidade no Brasil.

\section{Referências}


AGUIÃO, Silvia Rodrigues. Fazer-se no "Estado": uma etnografia sobre o processo de constituição dos "LGBT" como sujeitos de direitos no Brasil contemporâneo. Campinas. Tese de Doutorado em Ciências Sociais. Universidade Estadual de Campinas, 2014.

ALVAREZ, Marcos Cesar; SALLA, Fernando; DIAS, Camila Nunes. Das Comissões de Solidariedade ao Primeiro Comando da Capital em São Paulo. Tempo Social, v. 1, n. 25, 2013.

AZEVEDO, Rodrigo Ghiringhelli de; CIFALI, Ana Cláudia. Politica criminal e encarceramento no Brasil nos governos Lula e Dilma: elementos para um balanço de uma experiência de governo pós-neoliberal. Civitas, Porto Alegre, v. 15, n.1, 2015.

BARBOSA, Antonio Rafael. Grade de ferro? Corrente de ouro! Circulação e relações no meio prisional. Tempo Social: revista de sociologia da USP, v. 25, n. 1, 2013.

O baile e a prisão: onde se juntam as pontas dos segmentos locais que respondem pela dinâmica do tráfico de drogas no Rio de Janeiro. Cadernos de Ciências Humanas: Especiaria, v. 9, n.15, 2006.

BECKER, Howard. Métodos de pesquisa em ciências sociais. 4. ed. São Paulo: Hucitec, 1999.

BENEDETTI, Marcos Renato. Toda feita: o corpo e o gênero das travestis. Rio de Janeiro: Garamond, 2005.

BRASIL. Decreto Lei $\mathbf{n}^{\circ} \mathbf{2 . 8 4 8}$, de 7 de dezembro de 1940. Código Penal. Disponivel em: < http://www.planalto.gov.br/ccivil_03/decretolei/Del2848compilado.htm>. Acesso em: 05/07/2016.

Ministério da Justiça. Departamento Penitenciário Nacional. Levantamento Nacional de Informações Penitenciária INFOPEN: julho de 2016. Brasilia, 2016. Disponivel em: <http://depen.gov.br/DEPEN/noticias1 / noticias/infopen-levantamento-nacional-de-informacoes-penitenciarias2016/relatorio_2016_22111.pdf>. Acesso em: 24-04-2018.

BIONDI, Karina. Junto e misturado: uma etnografia do PCC. São Paulo: Terceiro Nome, 2010.

BUMACHAR, Bruna. Por meus filhos: usos das tecnologias de comunicação entre estrangeiras presas em São Paulo. In: COGO, Denise; ELHAJJI, Mohammed; HUERTAS, Amparo. (Org.). Diásporas, migrações, tecnologias da comunicação e identidades Transnacionais. Barcelona: Institut de la Comunicació, Universitat Autònoma de Barcelona, 2012.

BUTLER, Judith. Cuerpos que importan. Barcelona: Pardos, 2002.

Problemas de gênero: feminismo e subversão da identidade. 4. ed. Tradução de Renato Aguiar. Rio de Janeiro: Civilização Brasileira, 2012. 
CEARÁ. Lei Estadual de $\mathbf{n}^{\circ}$. 14.966, de 13 de julho de 2011. Disponível em: <http:/ / www.al.ce.gov.br/legislativo/legislacao5/leis2009/14582.htm>. Acesso em: 03/11/2014.

. Secretaria de Justiça e Cidadania. Portaria de $\mathbf{n}^{\circ}$ 0240/2010. Regimento Geral dos Estabelecimentos Prisionais do Estado do Ceará. Fortaleza, Ceará, 2010.

CHIES, Luiz Antônio Bogo. Do campo ao campo: análise da questão penitenciária no Brasil contemporâneo. Rev. O público e o privado, n. 26, 2015.

CUNHA, Manuela Ivone. Prisão e sociedade: modalidades de uma conexão. In: _. Aquém e além da prisão: cruzamentos e perspectivas. Lisboa: $90^{\circ}$ ed., 2008.

DIAS, Camila Nunes. Da pulverização ao monopólio da violência: expansão e consolidação do Primeiro Comando da Capital (PCC) no sistema carcerário paulista. São Paulo. Tese de Doutorado em Sociologia. Universidade de São Paulo, 2011.

FELTRAN, Gabriel de Santis. Crime e castigo na cidade: os repertórios da justiça e a questão do homicídio nas periferias de São Paulo. Caderno CRH, v. 23, n. 58, 2010.

FERREIRA, Guilherme Gomes. Travestis e prisões: a experiência social e a materialidade do sexo e do gênero sob o lusco-fusco do cárcere. Porto Alegre. Dissertação de Mestrado em Serviço Social. Pontifícia Universidade Católica do Rio Grande do Sul, 2014.

GODOI, Rafael. Fluxos em cadeia: as prisões em São Paulo na virada dos tempos. São Paulo. Tese de Doutorado em Sociologia. Universidade de São Paulo, 2015.

Para uma reflexão sobre efeitos sociais do encarceramento. Revista Brasileira de Segurança Pública, v. 5, n. 8, 2011.

GODOI, Rafael; MALLART, Fábio. Apresentação do Dossiê Dados e atualidade da pesquisa em prisão do Brasil. Aracê: Direitos Humanos em Revista, v. 4, n. 5, 2017.

GOFFMAN, Erving. Manicômio, prisões e conventos. São Paulo: Perspectiva, 1974.

KULIK, Don. Travesti: prostituição, sexo, gênero e cultura no Brasil. Rio de Janeiro: Fiocruz, 2008.

LOURENÇO, Arlindo da Silva. O espaço de vida do agente de segurança penitenciária no cárcere: entre gaiolas, ratoeiras e aquários. Curitiba: Juruá, 2011. 
MALLART, Fábio. Cadeias Dominadas: a Fundação CASA, suas dinâmicas e as trajetórias dos jovens internos. São Paulo: Terceiro Nome, 2014.

MARCUS, George. Ethnography in/of the world system: the emergence of mult-sited ethnography. Annual Review of Anthropology, v. 24, 1995.

NASCIMENTO, Francisco Elionardo de Melo. Entre grades, muralha e vivências: uma etnografia da ressocialização na Penitenciária Industrial Regional de Sobral. Sobral. Trabalho de Conclusão de Curso de Graduação em Serviço Social. Instituto Superior de Teologia Aplicada, 2015.

"Por bem menos se interdita um zoológico": apontamentos da condição histórica das prisões cearenses que culminou na crise penitenciária. Aracê: Direitos Humanos em Revista, v. 4, n. 5, 2017.

Travestilidades Aprisionadas: narrativas de experiências de travestis em cumprimento de pena no Ceará. Fortaleza. Dissertação de Mestrado Acadêmico em Sociologia. Universidade Estadual do Ceará, 2018.

PADOVANI, Natália Corazza. Sobre casos e casamentos: afetos e "amores" através de penitenciárias femininas em São Paulo e Barcelona. Campinas. Tese de Doutorado em Antropologia Social. Universidade Estadual de Campinas, 2015.

PASSOS, Amilton Gustavo da Silva. Uma ala para travestis, gays e seus maridos: pedagogias institucionais da sobrevivência no presídio central de Porto Alegre. Porto Alegre. Dissertação de Mestrado em Educação. Universidade Federal do Rio Grande do Sul, 2014.

PELÚCIO, Larissa. Abjeção e desejo: uma etnografia travesti sobre o modelo preventivo de AIDS. São Paulo: Annablume; Fapesp, 2009.

. Toda Quebrada na Plástica: Corporalidade e construção de gênero entre travestis paulista. Revista Campos, v. 6, n. 1, 2005.

SALLA, Fernando. A pesquisa na prisão: labirintos. In: LOURENÇO, Luiz Claudio; GOMES, Geder Luiz Rocha (Orgs.). Prisões e punição: no Brasil contemporâneo. Salvador: EDUFBA, 2013.

- Práticas punitivas no cotidiano prisional. Rev. O público e o privado, n. 26, 2015.

SALIH, Sara. Judith Butler e a Teoria Queer. Belo Horizonte: Autêntica, 2013.

SILVA, Hélio. Travestis: entre o espelho e a rua. Rio de Janeiro: Rocco, 2007.

TAETS, Adriana Rezende Faria. Abrindo e fechando celas: narrativas, experiências e identidades de agentes de segurança penitenciária femininas. 
São Paulo. Dissertação de Mestrado em Antropologia Social. Universidade de São Paulo, 2012.

TELLES, Vera da Silva; HIRATA, Daniel Veloso. Cidade e práticas urbanas: nas fronteiras incertas entre o ilegal, o informal e o ilícito. Estudos Avançados, v.21, n.61, 2007.

VALE, Alexandre Fleming Câmara. Voo da beleza: travestilidade e devir minoritário. Fortaleza. Tese de Doutorado em Sociologia. Universidade Federal do Ceará, Fortaleza, 2005.

WACQUANT, Loïc. Punir os pobres: a nova gestão da miséria nos Estados Unidos. 3. ed. ver. amp. Rio de Janeiro: Renavan, 2007.

- Forjando o estado neoliberal: trabalho social, regime prisional e insegurança social. In: BATISTA, Vera Malaguti (Org.). Loïc Wacquant e a questão penal no capitalismo neoliberal. Rio de Janeiro: Renavan, 2. ed. 2012.

ZAMBONI, Marcio. O barraco das monas na cadeia dos coisas: notas etnográficas sobre a diversidade sexual e de gênero no sistema penitenciário. Aracê: Direitos Humanos em Revista, v. 4, n. 5, 2017. 